\title{
The Influence of Oil Concentration, Nitrogen and Phosphorus Composition on Crude Oil Biodegradation by Epyzim and Mixed Cultures of Pseudomonas aeruginosa and Arthrobacter simplex
}

\author{
ERLIZANOOR $^{1 *}$ ANDLINAWATI HARDJITO ${ }^{2}$ \\ ${ }^{1}$ Department of Agroindustrial Technology, Faculty of Agricultural Technology; \\ ${ }^{2}$ Department of Aquatic Products Technology, Faculty of Fisheries and Marine Science, Institut Pertanian Bogor, \\ Darmaga Campus, Bogor 16880, Indonesia
}

\begin{abstract}
Biological methods have gained attention as an alternative treatment for oil degradation in pollution remediation. External and internal factors have a great influence on crude oil biodegradation. This experiment studied the effect of oil concentrations and ratios of Ammonium and Phosphate on oil degradation in mixed cultures of local strains of Pseudomonas aeruginosa and Arthrobacter simplex. The oil degradation ability of this mixed culture was compared to the dormant culture of Epyzim. The increase of oil concentration, from 1, 3, 5 and $10 \%(\mathrm{w} / \mathrm{v})$, significantly lowered the ability of both cultures to degrade the oil i.e from $83 \%$ for $1 \%$ oil concentration to $64 \%$ for $10 \%$ oil concentration using local strains. The local strains showed better capability compare to the dormant culture. Medium composition was designed by three levels of ammonium concentration (7.6, 37.9 and $\left.75.8 \mathrm{mg} \mathrm{l}^{-1}\right)$ and two levels of phosphate concentration $\left(2.0\right.$ and $\left.9.9 \mathrm{mg} \mathrm{1}^{-1}\right)$. The ratio of ammonium to phosphate of 3.8:1.0 in the growth media has resulted the maximum level of oil degradation, i.e $83 \%$ and $88 \%$, for dormant and local cultures respectively. The results suggest a potential usage of local microorganisms in degrading crude oil-polluted water.
\end{abstract}

Key words: oil pollution, oil biodegradation, Epyzim, Pseudomonas aeruginosa, Arthrobacter simplex

Applying chemical methods to degrade oil spill results in secondary pollutants caused by chemicals or surfactants, while physical method only concentrate the pollutant without removing it permanently. Thus, both methods are less efficient and less effective in the control of pollution problems. Biodegradation is an appropriate technique as the hydrocarbon pollutant is converted permanently by microorganisms into carbon dioxide and water, or converted into less toxic compounds.

Several hydrocarbon degraders have been isolated from the Indonesian environment and some of them showed high a capability to degrade hydrocarbons. Previous studies described a Pseudomonas aeruginosa produced biosurfactant with enhanced hexadecanes or as a mixture of long chain n-alkanes (Robert et al. 1989). N-alkanes are commonly found in nature (Wakeham et al. 1986; Kennicut 1988).

Hydrocarbon biodegradation is affected by internal and external factors. The first is the genotype of the microorganism while the second includes environmental factors such as temperature, $\mathrm{pH}$, oxygen and oil concentrations. In addition, the biodegradation is also influenced by the availability of nitrogen and phosphorous compounds (Ratledge 1992; Margesin and Schinner 2001). Microorganisms are able to use hydrocarbons such as thiopene, benzothiopene and dibenzothiopene as carbon sources (Fedorak and Westlake 1983; Arvin et al. 1988; Mueller et al. 1991). The nutrient composition, especially $\mathrm{C}, \mathrm{N}$ and $\mathrm{P}$, are important controllable factors in oil biodegradation.

The aim of this research is to investigate the influence of nitrogen and phosphorus composition on the degradation of crude oil employing a mixed culture of $P$. aeruginosa and

*Corresponding author, Phone/Fax: +62-251-8621974, E-mail: erlizanoor@yahoo.com
Arthrobacter simplex. The performance of the mixed culture was compared to commercial culture produced for the same purpose named Epyzim.

\section{MATERIALS AND METHODS}

Bacterial Cultures. Pseudomonas aeruginosa and A. simplex were isolated and acclimated from an oil contaminated area in Cepu, Central Java. The bacteria were cultured in tripticase soy agar (TSA). In addition, each bacterium was grown in Tauson medium containing $1 \mathrm{~g}\left(\mathrm{NH}_{4}\right)_{2} \mathrm{SO}_{4}, 0.3 \mathrm{~g}$ $\mathrm{MgSO}_{4} \cdot 7 \mathrm{H}_{2} \mathrm{O}, 0.05 \mathrm{~g} \mathrm{FeSO}_{4} \cdot 7 \mathrm{H}_{2} \mathrm{O}, 0.15 \mathrm{~g} \mathrm{KH}_{2} \mathrm{PO}_{4}$, $0.2 \mathrm{~g} \mathrm{~K}_{2} \mathrm{HPO}_{4} \cdot 3 \mathrm{H}_{2} \mathrm{O}, 0.6 \mathrm{~g} \mathrm{CaSO}_{4} \cdot 2 \mathrm{H}_{2} \mathrm{O}$ and added to $11 \mathrm{of}$ distilled water. Crude oil was used as a carbon source and added at concentration of $1.0 \mathrm{~g} \mathrm{l}^{-1}$. An imported commercial microorganism preparation called Epyzim was used as a reference. A $0.5 \mathrm{~g}$ aliquot of Epyzim powder was activated in $150 \mathrm{ml}$ media by adding $1.0 \mathrm{~g} \mathrm{l}^{-1}$ of crude oil as carbon source. Each culture was grown on a shaker at $120 \mathrm{rpm}$ at room temperature for 48 hours. All experiments were carried out in duplicate. The growth of microorganisms was monitored by observing the turbidity of media. The Optical Density of the media measured by using the Spectrophotometer at a wavelength of $550 \mathrm{~nm}$.

Media Composition. A $10 \%$ (v/v) of Epyzim culture was used as a starter. For the $P$. aeruginosa and $A$. simplex cultures, each was added at concentration of $5 \%(\mathrm{v} / \mathrm{v})$ as a mixed starter. Those starters were inoculated in Tauson media with variations of ammonium and phosphate ratio (7.6:2.0, 7.6:9.9, 37.9:9.9 and 75.8:9.9) or $\mathrm{N}: \mathrm{P}$ ratio of 3.8, 0.8, 3.8 and 7.6. The ammonium and phosphate sources were $\left(\mathrm{NH}_{4}\right) \mathrm{SO}_{4}$, $\mathrm{KH}_{2} \mathrm{HPO}_{4}$, and $\mathrm{K}_{2} \mathrm{HPO}_{4}$. To each media having various N:P ratios was added $10.0 \mathrm{~g} \mathrm{l}^{-1}$ of crude oil (Virginia Oil Company, East Kalimantan). The experiments were conducted in duplicate. The cultures were grown for 21 days at room 
temperature on a shaker at $120 \mathrm{rpm}$. Sampling was undertaken daily during the culture growth phase. The oil residue following each treatment was analysed to determine the hydrocarbon degradation rate by applying the gravimetric method. The oil content was measured by extracting samples with hexane. The $\%$ of oil degraded at the end of each experiment was determined using the following formula:

$$
\frac{\text { initial oil content }-\begin{array}{c}
\text { average oil content at } \\
\text { stationary phase }
\end{array}}{\text { initial oil content }} \times 100 \%
$$

The Influence of Oil Concentration. Oil concentrations used consisted of $1,3,5$ and $10 \%$ (w/v). The bacteria were grown in $150 \mathrm{ml}$ of Tauson medium agitated at $120 \mathrm{rpm}$ for 21 days at room temperature. The number of cell in both cultures are similar for each inoculum and measured as an $\mathrm{OD}_{550}$ equal 1 . The bacteria added at $10 \%$ of the working volume. At the end of cultivation, the oil residue was measured in duplicate to determine the degradation rate.

\section{RESULTS}

Oil Biodegradation in Tauson Media. A mixed culture of P. aeruginosa and A. simplex degraded oil to a lower level than Epyzim. At oil concentration of $1 \%$, Epyzim degraded oil by up to $83 \%$ at N/P of 3.8. The ratio of nitrogen and phosphorus was determined based on the ammonium and phosphate salt added to the medium. At the highest N/P

Table 1 Oil biodegradation at various ammonium phosphate ratio $(\mathrm{N} / \mathrm{P})$ at an initial oil concentration of $1 \%$ for 21 days

\begin{tabular}{ccccc}
\hline $\mathrm{NH}_{4} \mathrm{mg} \mathrm{l}^{-1}$ & \multirow{2}{*}{$\mathrm{PO}_{4} \mathrm{mg} \mathrm{l}^{-1}$} & \multirow{2}{*}{$\mathrm{N} / \mathrm{P}$} & \multicolumn{2}{c}{ Percentage of oil degraded (\%) } \\
\cline { 4 - 5 } & & & Epyzim & Mixed culture* \\
\hline 7.6 & 2.0 & 3.8 & 83.0 & 87.7 \\
7.6 & 9.9 & 0.8 & 75.0 & 80.0 \\
37.9 & 9.9 & 3.8 & 81.7 & 80.7 \\
75.8 & 9.9 & 7.6 & 70.7 & 80.0 \\
\hline
\end{tabular}

*A mixed culture of Pseudomonas aeruginosa and Arthrobacter simplex. The equal amounts of Epyzim and mixed culture i.e 10\% (v/v) at $\mathrm{OD}_{550}=1$ were used at an initial cultivation.

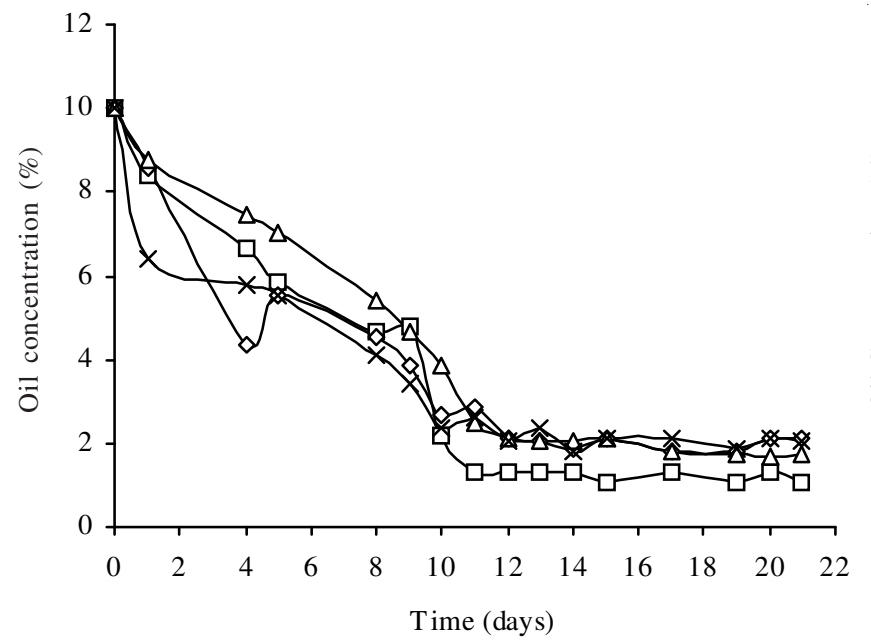

which was 7.6, the Epyzim bacteria degraded oil up to $70.7 \%$. At the lowest N/P (0.8), the Epyzim bacteria degraded oil up to $75.0 \%$, which is about $9.6 \%$ lower than the highest degradation value achieved at N/P of 3.8 ( Table 1).

An equal mixed culture of $P$. aeruginosa and A. simplex at the lowest $\mathrm{N} / \mathrm{P}(0.8)$ resulted in oil degradation up to $80.0 \%$. At higher N/P (3.8) resulted from the ratio of ammonium: phosphate of 2.0:7.6 and 37.9:9.9, the mixed culture of $P$. aeruginosa and $A$. simplex degraded oil by up to 87.7 and $80.7 \%$, respectively.

The mixed culture $P$. aeruginosa and A. simplex showed a degradation level higher than Epyzim (Fig 1), this also confirmed by the specific growth rate of a mixed culture that higher than Epyzim for all N/P ratio as shown in Table 2. N/P of 3.8 was the optimal condition for both cultures. N/P ratio did not influence the degradation time. For all N/P, a mixed culture of $P$. aeruginosa and $A$. simplex and Epyzim reached stationary growth phase after 9 days and 11 days cultivation, respectively (Fig 2). The investigation showed that N/P of 3.8 was the optimal condition for bacterial growth and oil degradation and the ratio was used for further experiments.

The Influence of Oil Concentration on Biodegradation. In the media containing an ammonium and phosphate ratio of 7.6:2.0 at various initial oil concentrations, results showed that increasing the initial oil concentration decreased oil degradation (Fig 3). In the mixed culture of $P$. aeruginosa and A. simplex with the initial oil concentration of $1,3,5$, and $10 \%$ resulted in oil degradation of up to $83,77,74$ and $65 \%$, respectively after 21 days cultivation. For Epyzim under the same conditions, oil degradation reached 80, 77, 71 and $62 \%$.

The optimum biodegradation for both cultures is presented as a histogram in Fig 4. This shows that the performance of mix culture $P$. aeruginosa and A. simplex is slightly better than for the Epyzim. Both cultures were able to degrade oil at the highest concentration tested $(10 \% \mathrm{w} / \mathrm{v})$. The time required to degrade the various oil concentrations was between 10-15 days, where the cultures reached the stationary phase.

Fig 1 Oil degradation by Epyzim and mixed culture of Pseudomonas aeruginosa and Arthrobacter simplex. $\square: 2 \mathrm{mg} \mathrm{l}^{-1} \mathrm{PO}_{4}+7.6 \mathrm{mg} \mathrm{l}^{-1} \mathrm{NH}_{4}$ $(\mathrm{N}: \mathrm{P}=3.8) ; \diamond: 9.9 \mathrm{mg} \mathrm{l}^{-1} \mathrm{PO}_{4}+7.6 \mathrm{mg} \mathrm{l}^{-1} \mathrm{NH}_{4}(\mathrm{~N}: \mathrm{P}=0.8) ; \triangle: 9.9 \mathrm{mg} \mathrm{l}^{-1} \mathrm{PO}_{4}+37.9 \mathrm{mg} \mathrm{l}^{-1} \mathrm{NH}_{4}(\mathrm{~N}: \mathrm{P}=3.8) ; \mathrm{x}: 9.9 \mathrm{mg} \mathrm{l}^{-1} \mathrm{PO}_{4}+75.8 \mathrm{mg} \mathrm{l}^{-1} \mathrm{NH}_{4}$ $(\mathrm{N}: \mathrm{P}=7.6)$. 

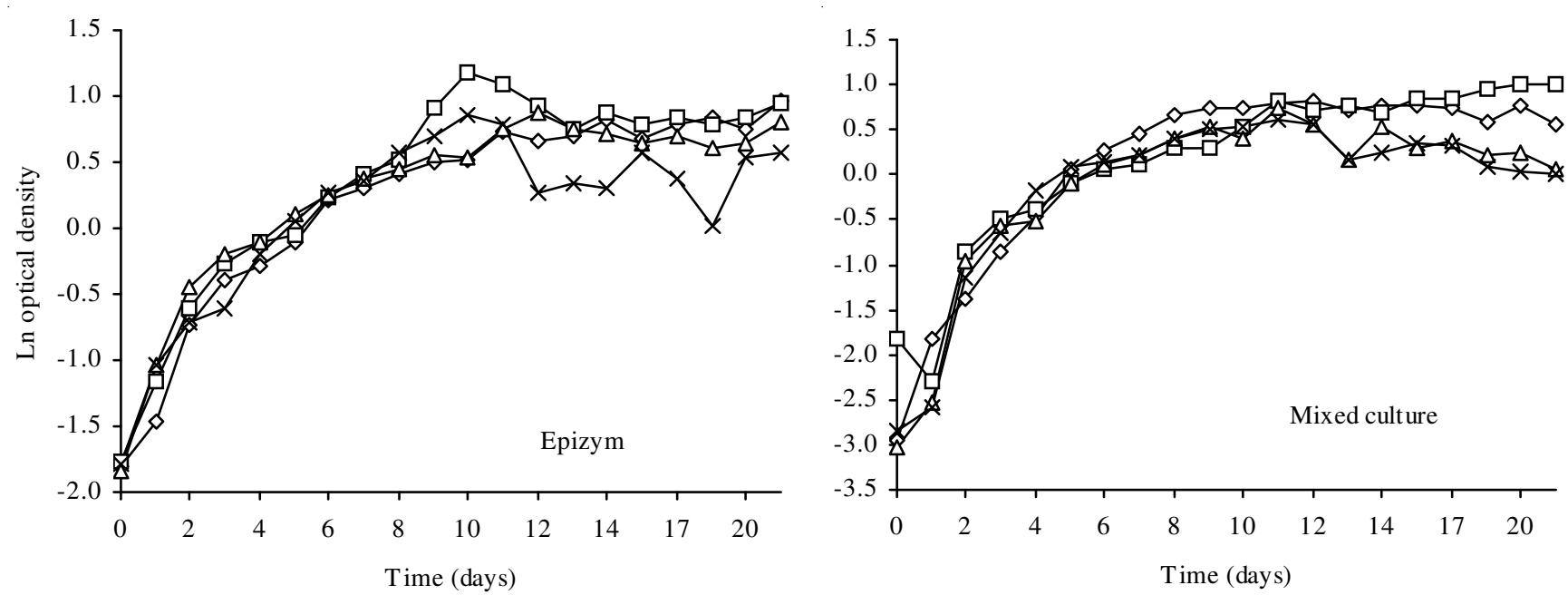

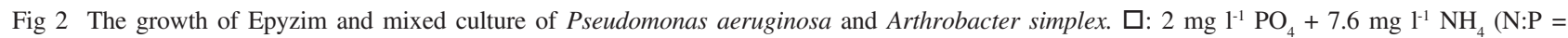
3.8); $\diamond: 9.9 \mathrm{mg} \mathrm{l}^{-1} \mathrm{PO}_{4}+7.6 \mathrm{mg} \mathrm{l}^{-1} \mathrm{NH}_{4}(\mathrm{~N}: \mathrm{P}=0.8) ; \triangle: 9.9 \mathrm{mg} \mathrm{l}^{-1} \mathrm{PO}_{4}+37.9 \mathrm{mg} \mathrm{l}^{-1} \mathrm{NH}_{4}(\mathrm{~N}: \mathrm{P}=3.8) ; \mathrm{x}: 9.9 \mathrm{mg} \mathrm{l}^{-1} \mathrm{PO}_{4}+75.8 \mathrm{mg} \mathrm{l}^{-1} \mathrm{NH}_{4}\left(\mathrm{~N}^{4} \mathrm{P}=7.6\right)$.
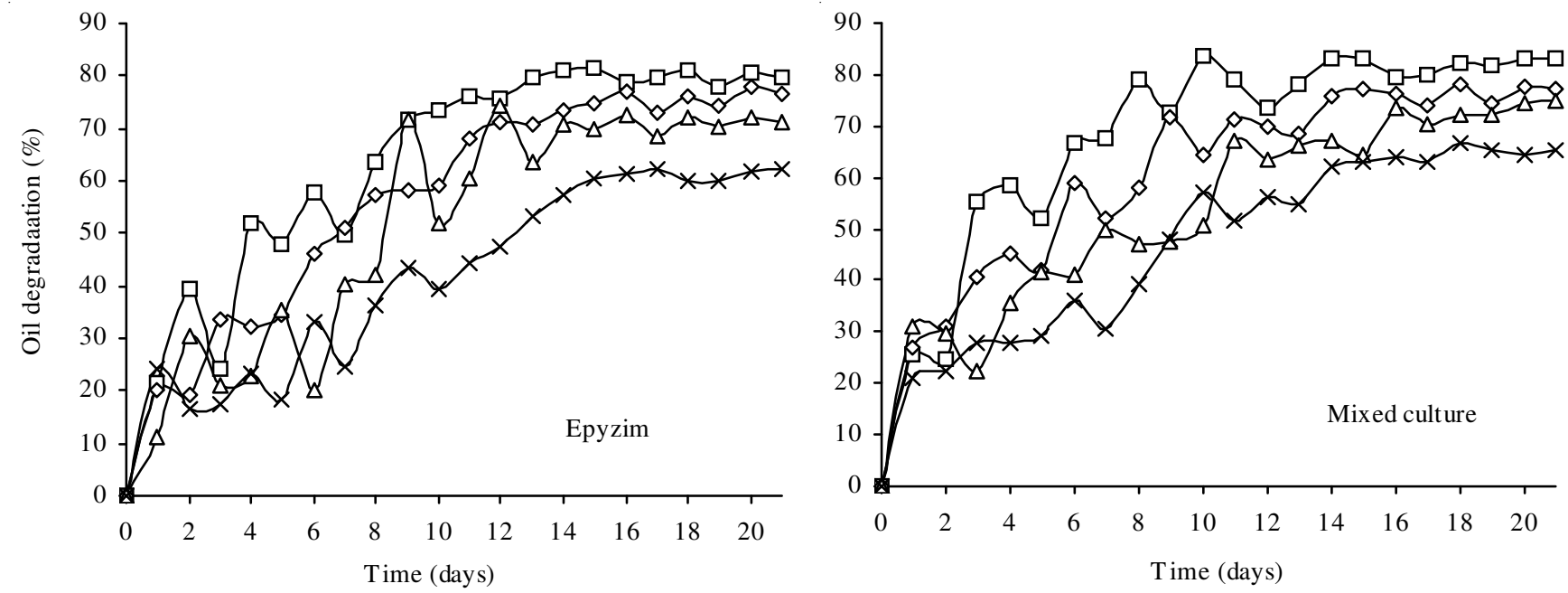

Fig 3 Percentage of oil degradation by epyzim and mixed culture of Pseudomonas aeruginosa and Arthrobacter simplex during microbial growth at various oil concentrations. $\square$ : oil concentration of $1 \%$; $\diamond$ : oil concentration of $3 \%$; $\triangle$ : oil concentration of $5 \%$; x: oil concentration of $10 \%$.

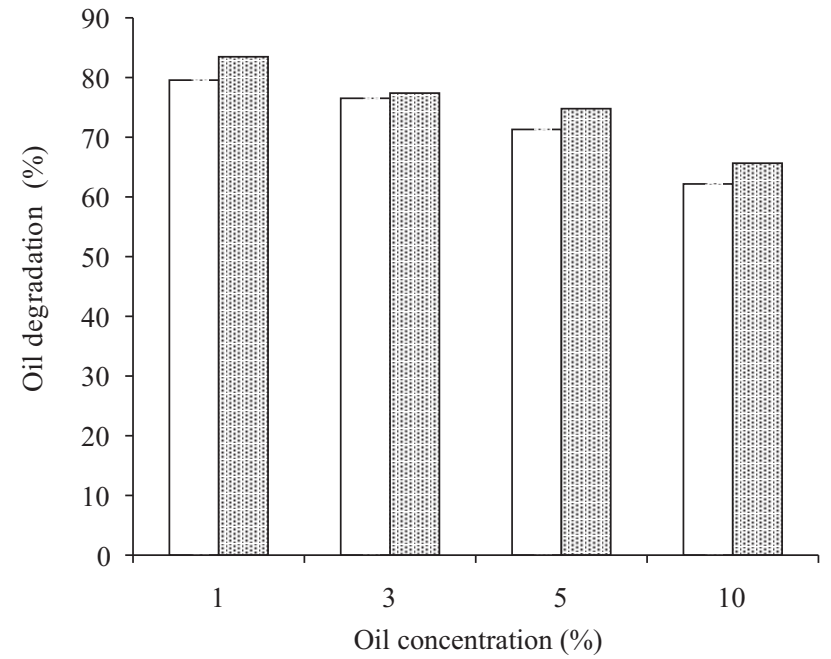

Fig 4 The comparison of oil degradation by Epyzim and mixed culture of Pseudomonas aeruginosa and Arthrobacter simplex. $\square$ : Epyzim,
Table 2 Specific growth rate of Epyzim and mixed culture at various ammonium phosphate ratio $(\mathrm{N} / \mathrm{P})$

\begin{tabular}{ccccc}
\hline $\mathrm{NH}_{4} \mathrm{mg} \mathrm{l}^{-1}$ & $\mathrm{PO}_{4} \mathrm{mg} \mathrm{l}^{-1}$ & $\mathrm{~N} / \mathrm{P}$ & \multicolumn{2}{c}{ Specific growth rate, $\mu\left(\right.$ day $\left.^{-1}\right)$} \\
\cline { 4 - 5 } & & & Epyzim & Mixed culture \\
\hline 7.6 & 2.0 & 3.8 & 0.33 & 0.52 \\
7.6 & 9.9 & 0.8 & 0.26 & 0.27 \\
37.9 & 9.9 & 3.8 & 0.32 & 0.52 \\
75.8 & 9.9 & 7.6 & 0.31 & 0.47 \\
\hline
\end{tabular}

\section{DISCUSSION}

The highest oil degradation for both cultures was achieved at a N/P ratio of 3.8. This was produced by the ratios of ammonium and phosphate of 7.6:2.0 and 37.9: 9.9 (Table 1). The results indicate that the N/P ratio is an important factor affecting the growth of bacteria and oil degradation (Fig 1 and 2). The lower level of oil degradation is due to the inhibition of bacterial growth caused by unbalanced nutrients $(\mathrm{N} / \mathrm{P})$. At a N/P ratio of 0.8 , resulting from the ammonium and 
phosphate addition at concentration of 7.6 and $9.9 \mathrm{mg} \mathrm{l}^{-1}$, respectively, the added phosphate was excessive. Similarly, at a N/P ratio of 7.6, the added ammonium $\left(75.8 \mathrm{mg} \mathrm{l}^{-1}\right)$ was higher than needed. These conditions resulted in a lower oil degradation. For biodegradation of light crude oil the N/P molar ratios between 10:1 and 20:1 were optimal for oil degradation (Nagwa et al. 1999). It can be concluded that unbalance $\mathrm{N} / \mathrm{P}$ results in unfavourable conditions for microbial growth that finally decreases oil degradation.

The equal mixed culture of $P$. aeruginos $a$ and $A$. simplex degraded oil better than Epyzim. The oil degradation of both cultures was in the range of $62-83 \%$ (Fig 3). The values obtained agreed with previous investigations, which was between 45-90\% degradation (Swannell et al. 1996) and 75\%$87.5 \%$ degradation of crude oil by addition of NPK fertilizer (Ijah et al. 2008). Epyzim consists of dormant bacteria that require an adaptation phase before degrading oil, while $P$. aeruginosa and $A$. simplex are local cultures that are better adapted to the environmental conditions. The experiments were conducted at room temperature which is close to that of their original habitat.

The data in Fig 4 indicate that at various concentrations of oil, the mixed culture of $P$. aeruginosa and A. simplex degraded oil better than Epyzim. The single culture of $P$. aeruginosa was able to degrade oil up to $25 \%$ at an initial concentration of $1 \%(\mathrm{w} / \mathrm{v})$ over 14 days cultivation (Udiharto 1992). In our experiments with a degradation time between 10-15 days, the data showed 70 to $80 \%$ oil degradation (Fig 3). Previous investigations indicated that a mixed culture of $P$. aeruginosa and A. simplex grew and degraded oil to a significantly higher level than if one used a single culture (Hardjito 2002). In addition the percentages of degraded oil were 58.9, 63.8 and 68.9, respectively. The reason why a mixed culture gave better performance than a monoculture was due to the production of biosurfactant during the growth period of $P$. aeruginosa (Robert et al. 1989).This degradation time with this mixed cultures is also less than the degradation time employing mixed cultures of $P$. aeruginosa, $P$. stutzeri and B. subtilis, which was 60 days (Swannell et al. 1996). These results show that $P$. aeruginosa and $A$. simplex work better together to degrade oil.

The results of our investigation indicated that mixed culture of $P$. aeruginosa and A. simplex has potential to be developed as a biological agent to degrade oil. In term of ease of use, Epyzim is more practical, while a mixed culture of $P$. aeruginosa and $A$. simplex is better in term of biodegradation ability. It is suggested that the development of a dormant mixed culture of $P$. aeruginosa and $A$. simplex would increase the practicality of this improved procedure.

\section{REFERENCES}

Arvin E, Jensen B, Aamand J, Jorgensen C. 1988. The potential for free living ground water bacteria to degrade aromatic hydrocarbons and heterocyclic compounds. Water Sci Technol 20:109-118.

Fedorak PM, Westlake DWS. 1983. Microbial degradation of organic sulfur compounds in Prudhoe bay crude oil. Can J Microbiol 29:291-296.

Hardjito L. 2002. The treatment of petroleum industrial waste and bioremediation of contaminated site: The Indonesia experience. In: Proceeding of the ASEM Conference on Bioremediation. Ha Noi, Vietnam, Sep 24-27, 2002. p1-14

Ijah UJJ, Safiyanu H, Abioye OP. 2008. Comparative study of biodegradation of crude oil in soil amended with chicken dropping and NPK fertilizer. Sci World J 60:63-67.

Kennicut MC. 1988. The effect of biodegradation on crude oil bulk and molecular composition. Oil Chem Pollut 4:89-112.

Margesin R, Schinner F. 2001. Bioremediation (natural attenuation and biostimulation) of diesel-oil-contaminated soil in an Alpine glacier skiing area. Appl Environ Microbiol 67:3127-3133.

Mueller JG, Lantz SE, Blattman BO, Chapman PJ. 1991. Bench scale evaluation of alternative biological treatment processes for remediation of pentachlorophenol and creosote contaminated materials slurry phase bioremediation. Environ Sci Technol 25:1055-1061.

Nagwa MA, Nagwa MM, Magdy EM. 1999. Crude oil biodegradation by naturally inhabiting mixed bacterial culture under different environmental factors. Pak J Biol Sci 2:1211-1218.

Ratledge C. 1992. Mini-review compilation biodegradation and biotransformation of oil and fats. J Chem Tech Biotechnol 55:397414.

Robert M, Mercade ME, Bosch MP, Parra LL. 1989. Effect of the carbon source on biosurfactant by Pseudomonas aeruginosa 44T1. Biotechnol Lett 11:871-874.

Swannell RPJ, Lee K, McDonagh M. 1996. Field evaluation of marine oil spill bioremediation. Microbiol Rev 60:342-365.

Udiharto M. 1992. Aktivitas mikroba dalam degradasi minyak bumi. Dalam: Prosiding Diskusi Ilmiah VII. Hasil Penelitian LEMIGAS. Jakarta, Indonesia, Feb 11-13, 1992.

Wakeham SG, Canuel EA, Doering PH. 1986. Behavior of aliphatic hydrocarbons in coastal seawater mecososm experiment with C14 Octadecane and C-14 Decane. Environ Sci Technol 20:574580 . 